Original Research Paper

\title{
Honeycomb Sandwich Specimens Made of PLA and Produced Via 3D FDM Printing Process: An Experimental Study
}

\author{
Salvatore Brischetto and Roberto Torre \\ Department of Mechanical and Aerospace Engineering, Politecnico di Torino, Turin, Italy
}

\author{
Article history \\ Received: 27-02-2020 \\ Revised: 06-04-2020 \\ Accepted: 23-05-2020 \\ Corresponding author: \\ Salvatore Brischetto \\ Department of Mechanical and \\ Aerospace Engineering, \\ Politecnico di Torino, Turin, \\ Italy \\ Email: salvatore.brischetto@polito.it
}

\begin{abstract}
In recent years, the 3D Fused Deposition Modelling (FDM) technology, usually employed for the production of nonstructural objects, has been also used by the present authors for the production of small structural elements where the applied loads are moderate. A typical application could be the production of small Unmanned Aerial Vehicles (UAVs) where stresses are not excessive. In these cases, the FDM technique can use polymers such as Acrylonitrile Butadiene Styrene (ABS) and PolyLacticAcid (PLA). The present work is an extension of a past authors' work where some sandwich configurations were proposed combining different materials (ABS or PLA) and different cores (homogeneous or honeycomb). In the present study, only PLA specimens embedding honeycomb cores are analyzed in order to understand if this selected lamination scheme could lead to an important weight reduction without significant decreases of mechanical properties. A capability analysis is performed on the geometrical parameters of the specimens (also comprising the weight) in order to investigate the stability of the printing process. A three-point bending test is conducted to evaluate the linear bending Young modulus and the ultimate bending stress. These mechanical properties are post-processed in order to conduct a capability analysis to propose the upper and lower specification limits to be used with confidence in appropriate structural analyses.
\end{abstract}

Keywords: Fused Deposition Modeling, 3D Printing Process, Additive Manufacturing, Sandwich Specimens, Honeycomb Core, Three-Point Bending Tests, Capability Analysis

\section{Introduction}

Additive Manufacturing (AM) technologies usually produce layer-by-layer elements, a possible classification of the different AM methods can be found in Levy et al. (2003) where several materials and manufacturing techniques were deeply discussed. Additive Manufacturing (AM) technology was patented in 1984 and its main feature is the addition of material using different procedures (e.g., based on powder or wire) in place of the subtraction of material from a raw part. The promising future of this technology was shown in Lu et al. (2015) where the great potential of AM was clearly indicated via the discussion of several possible applications. In Brischetto et al. (2017c; 2017d), the main investigated technologies were the Selective Laser Sintering (SLS) and the Fused Deposition Modelling (FDM). These methodologies, combined with the Computer Aided Design (CAD), provide fundamental advantages. Numerical, analytical and experimental knowledges and models are mandatory to exploit the potential advantages given by $3 \mathrm{D}$ printing in the production of modern systems and structures for aerospace, mechanical, civil and biomedical engineering fields. The first author collaborated in a project where the SLS technology was employed for the production of a metallic multifunctional sandwich panel embedding a trabecular core; this configuration was used to replace the typical de-icing and anti-icing systems employed in modern aircrafts in order to obtain important advantages in terms of performances and weights (Bici et al., 2018; Ferro et al., 2018; 2017b; 2017c). In these studies, analytical, numerical and experimental simulations were opportunely combined as clearly discussed in Yang et al. (2015). The FDM technology is not usually employed for the production of structural elements because of the uncertainty in determining the mechanical characteristics of the elements produced via this method. In recent years, the present authors tried to overcome this great limitation by means of a deep study conducted on FDM 
printed elements made of Acrylonitrile Butadiene Styrene (ABS) and PolyLacticAcid (PLA). These materials combined with FDM technology can be used for the production of small structural elements that can be subjected to limited values of loads. Typical examples are the studies conducted for the design and production of a small multipurpose modular drone made of PLA and entirely produced via FDM technology (Brischetto et al., 2016a; 2016b). This innovative drone was called PoliDrone and all the details can be found in the related patent application definitely accepted in 2018 (Brischetto et al., 2015).

Recently, the present authors worked on the investigation of the mechanical properties of PLA and ABS elements produced via FDM technology. Brischetto et al. (2017b) proposed compression tests for ABS specimens where the ultimate static compression stress was defined and a preliminary buckling analysis was performed to understand the appropriate slenderness ratio. ABS and PLA specimens printed via FDM technology were experimentally investigated in Ferro et al. (2016) and Torre et al. (2018) where their mechanical characterization was proposed in analogy with composites embedding unidirectional long fibres. The hypothesis of orthotropic behavior could allow the determination of the nine basic engineering constants in order to build the 3D matrix of elastic coefficients that should be used for the structural Finite Element analysis of small structural drone elements. A more general statistical machine process evaluation of the FDM production of polymeric specimens employed in the experimental mechanical characterization was proposed in Brischetto et al. (2020). The present work is an extension of some past authors' works about the mechanical evaluation of sandwich specimens made of polymeric materials and produced via the FDM printing technique. Here, the most promising configuration (two external skins and an internal honeycomb core produced by means of a single extruder and made of the same PLA) is deeply investigated by proposing a complete statistical and capability analysis for the dimensions (in order to evaluate the machine process) and for the mechanical properties (in order to investigate the potentials for future structural applications). In Brischetto et al. (2017a; 2018) and Ferro et al. (2017a) several sandwich specimens were preliminary analyzed by considering homogenous or honeycomb cores and by using different combinations of PLA and ABS for the core and for the skins. In these works, the honeycomb sandwich specimens using the same PLA for the core and the skins were spotted as the most promising configuration: for this reason, such a configuration has been deeply investigated in a systematic way in the present paper.

The most interesting works found in the open literature about the main AM technologies applied to polymeric materials are discussed in the present section. 3D printed implantable devices were studied by Carlier et al. (2019) The feasibility of Fused Deposition Modelling was analyzed, together with the effects of some printing parameters on physical properties of devices, e.g., the layer thickness, the deposition rate and the temperature were investigated. Further interesting biomedical applications of 3D printing were discussed in Raj et al. (2018). However, as clearly indicated in Dana et al. (2019), there is an uncertainty in the definition of mechanical properties of Polymers Additive Manufacturing (PAM) products. The list of mechanical properties that must be comprehensively determined is still long. The behaviour of AM produced elements under different load types (e.g., compressive, impact, fatigue, bending and tensile ones) is not yet fully defined (Dizon et al., 2018). A material can be successfully employed for 3D printing operations if several fundamental conditions are met. These conditions were deeply discussed in Duty et al. (2018). El Moumen et al. (2019) studied 3D FDM printed polymer composites to understand if there was an influence on the mechanical properties due to pores formation. The homogenization technique based on the RVE method was used to study their mechanical behaviour. Therefore, the process parameters influenced the tensile properties of the 3D FDM printed ULTEM 9085 polymer. Gebisa and Lemu (2019) analyzed these influences by means of a full factorial design of experiment. Harshitha and Rao (2019) employed PolyLacticAcid (PLA) and Acrylonitrile Butadiene Styrene (ABS) materials to product a nut and a bolt by means of the FDM 3D printing technology, the commercial ANSYS software was employed for the finite element structural analysis. PLA and ABS were compared with Nylon 6 in the study by Lay et al. (2019) where physical and mechanical performances were investigated when fused deposition modeling and conventional injection molding processes were used. Mishra and Senthil (2020) printed bi-material laminate parts with different raster orientations by using FDM technique, the mechanical behaviour was described using Classical Lamination Theory (CLT). PolyLactic Acid (PLA) and PolyLactic Acid Carbon Black (PLA CB) were selected as feedstock materials to print bi-material structures. The use of FDM technology was also extended to the production of continuous fiber reinforced thermoplastic composites; in order to perform this process, Heidari-Rarani et al. (2019) developed an innovative extruder for the FDM technology. An interesting revision work about different technologies (e.g., Fused Deposition Modeling (FDM), Laminated Object Manufacturing (LOM), StereoLithography (SL), Extrusion and Selective Laser Sintering (SLS)) applied to the 3D printing of fiber reinforced polymers was proposed by Parandoush and Lin (2017). The review by 
Popescu et al. (2018) remarked the importance in the current research of the following features: practical and useful aspects, key process parameters and related limitations, applications of the results in further studies and real cases. Fused Deposition Modeling (FDM) technology and the ABS material are widely used in additive manufacturing. An experimental procedure to determine the optimum combination of manufacturing parameters was proposed by Sagias et al. (2018), to improve the mechanical properties of the 3D printed components. Sarvestani et al. (2018) implemented semi-analytical and finite element approaches and they conducted experimental impact tests to evaluate the performance of 3D printed sandwich panels having low weight. Song et al. (2017) produced PLA blocks with high density by means of 3D printing technology, the elasto-plastic material response was found to be orthotropic and also characterised by a strong tensioncompression asymmetry: in fact, the material was tougher when loaded in the extrusion direction than in the transverse direction. Carbon fiber reinforced polymer sandwich structures produced via 3D printing were studied in Sugiyama et al. (2018) where sandwich structures with honeycomb, rhombus, rectangle and circle core shapes (produced as a single piece) were investigated. The functional properties of the sandwich structures were quantified by shape evaluations and by three-point bending tests. Three-point bending tests showed maximum load and flexural modulus improved when the effective density increased, this consideration was valid for all core shapes. These thermoplastic composites can be classified into particle-, fiber- and nanomaterial-based composites and also into polymer blends; in all these cases, the higher FDM temperature could improve the printing performances of these thermoplastic composites (Valino et al., 2019). Due to the intrinsically limited mechanical properties and functionalities of printed pure polymer parts, there is a critical need to develop printable polymer composites with high performances (Wang et al., 2017). The influence of some process parameters (layer height, extrusion temperature and material density) on the tensile strength of FDM 3D printed specimens was studied by Yadav et al. (2020) Several materials were investigated, e.g., PETG, ABS and multi-materials including $60 \%$ ABS $+50 \%$ PETG. Several combinations of materials and process parameters were studied using the ASTM D638-(IV) standard test specimen. A similar study was conducted by Yao et al. (2019), they evaluated the ultimate tensile strength of FDM PLA materials when printing angles changed. A theoretical model was firstly established to predict the ultimate tensile strength of FDM PLA materials, this model was based on transverse isotropic hypothesis, classical lamination theory and Hill-Tsai anisotropic yield criterion. Then, the verification was performed by means of tensile experiments. Finally, Zhao et al. (2019) proposed two new theoretical models to predict the tensile strength and Young modulus of FDM PLA materials with different printing angles and layer thicknesses. Firstly, a strength theoretical model was established based on transversely isotropic material hypothesis and Tsai-Hill strength criterion. Then, a Young modulus theoretical model was developed for the orthotropic material hypothesis under plane stress state.

The present work is organized in the following way: after a brief description of the geometry, material and lamination of the investigated sandwich specimens and a general description of the production process, a capability and statistical analysis for the main dimensions and the weight of the 12 produced specimens is presented in order to evaluate the machine and production process. Then, the typical three-pointbending test, here used for the flexural mechanical characterization of sandwich specimens, is described. After the collection of the main mechanical results, a statistical and capability analysis is performed in order to evaluate the main design values. Finally, the most important conclusions and further developments are briefly discussed.

\section{Sandwich Draw and Production}

The sandwich specimens were printed using the professional Funmat HT printer. The employed printing technology is the Fused Deposition Modelling (FDM), also called Fused Filament Fabrication (FFF) in the open literature. A raw cylindrical thermoplastic filament with diameter equals $1.75 \mathrm{~mm}$ is the starting material for the process. In the present work, PLA has been used. It has been dragged into the hot-end and melted; then, it has been extruded on a heated glass bed. Once the first layer has been completed, the bed moves downward and the extruder deposits a second layer on the top of the first printed one and so on for the other layers. The distance measured from the extruder to the printing plane (which could be the bed in the case of the first layer printing, or the previous layer in the case of the next layers printing) is the layer height. The user can set the path followed by the nozzle during the printing process. The peripheral beads are usually deposited to follow the external contour (and the internal one, if it exists) of the object and they allow a good surface finish for the final element. When the contour deposition is concluded, the extruder fills the internal section. This infill can be also customized and it is usually chosen as a function of the shape and geometry of the element. These described printing parameters are only two of the several possible settings that can be chosen in the process. These values significantly affect the mechanical tensile, compression 
and flexural properties of the printed elements (Yadav et al., 2020; Yao et al., 2019). The main parameter values were set thanks the experience gained by the authors in past works about the FDM technology.

The build temperature is the temperature of the extruder or nuzzle and it depends on the employed polymer. In the case of PLA, a nozzle temperature equals $200^{\circ} \mathrm{C}$ has been set.

The layer height represents how thick is each layer, a value equals $0.1 \mathrm{~mm}$ was set in order to improve the surface finish of the piece.

The bed temperature is the temperature of the printing surface. A temperature equals $30^{\circ} \mathrm{C}$ has been set for the PLA in order to improve the general adherence and to limit the shrinkage effect. In fact, both these effects are due to a rapid cooling of the element that must be avoided.

Perimeters is the number of peripheral beads chosen for the printing of the specimens. Three peripheral beads were printed in order to overcome the printing difficulties, due to the specific geometry of the internal core, that occurred in unsupported peripheral areas.

The raster orientation or raster angle is the chosen angle for each deposited bead, evaluated with respect to a reference axis of the printing plane. The choice of the raster angle is possible when a rectilinear pattern is selected for the internal infill. In the proposed sandwich specimens, the external skins are printed with a crisscross lamination scheme where the stacking sequence is $\left[45^{\circ}-45^{\circ}\right]$. The internal honeycomb core is printed without this choice for the internal infill because the thickness of the walls of each hexagon element are thick enough to be build with a single bead only. Therefore, the filling strategy parameters are meaningless for this physical layer.

The internal infill is the percentage of volume occupied by the extruded polymer. A value equals $100 \%$ has been employed for the homogeneous external skins while this printing parameter is meaningless for the internal honeycomb core as already explained in the previous points.

The experimental tests conducted for the evaluation of the flexural mechanical properties of un-reinforced and reinforced plastic materials can be based on the ASTM D790 reference standard (ASTM, 2017a) or on the ASTM D6272 reference standard (ASTM, 2017b). In both the standards, the method considers simply supported specimens, the difference lies in the way the load is applied. In the ASTM D790 the method is performed as a three-point loading test, while a fourpoint loading test is conducted by means of the ASTM D6272 reference standard. The specimen is always supported on two external points and the load is applied by means of a single and central nose in the case of the ASTM D790 reference standard (ASTM, 2017a) and by means of two symmetrically located noses in the case of the ASTM D6272 reference standard (ASTM, 2017b). The two tests differ in the localization of the maximum axial fiber stress because the maximum bending moment is differently located. The ASTM D790 reference standard (ASTM, 2017a) suggests the use of the ASTM D6272 reference standard (ASTM, 2017b) only when the surface subjected to tensile stresses does not break or yield within a deformation limit equals $5.0 \%$. This feature has been verified by means of a preliminary assessment. Therefore, the rules suggested by ASTM D790 reference standard (ASTM, 2017a) can be used with confidence. Then, the subsequent results confirmed the correctness of the use of the ASTM D790. The tests have been conducted by means of the following target geometrical parameters. A span between the supports equals $90 \mathrm{~mm}$ and a span-to-depth ratio equals 18 were chosen. Therefore, the thickness of the specimens is $5 \mathrm{~mm}$. In order to obtain an appropriate margin and to prevent the specimen slipping, the length of the specimen is $110.50 \mathrm{~mm}$. The width of each specimen is $23.67 \mathrm{~mm}$, this last parameter is a function of the number of hexagons in the transverse direction and their apothem and wall thickness.

The main aim of the present work is the investigation of possible benefits obtained from the use of sandwich structures printed by means of the 3D FDM technology. Investigated sandwich specimens have external homogenous thin skins made of PLA and a thick internal honeycomb PLA core. The proposed lamination sequence should give a marginal increase of the total weight and a consequential important increasing of the bending stiffness. In Brischetto et al. (2018), several sandwich configurations were preliminary investigated by considering honeycomb or homogeneous cores and different combinations of PLA and ABS for the skins and the cores. One of the most promising configuration was that here investigated in depth. The sandwich is made of PLA embedding two external homogeneous skins and an internal honeycomb core, all the element has been produced by means of a single extruder which prints both the skins and the core in sequence. The $2 \mathrm{D}$ drawing of the proposed specimen is shown in Fig. 1 where all the target geometrical values are given. The two external skins have a global thickness equals $2 \mathrm{~mm}$. The thickness of the honeycomb core is $3 \mathrm{~mm}$. The hexagon is the fundamental cell of the honeycomb core and it is repeated across the width and the length of the specimen. The apothem of the internal hexagon is 2.25 $\mathrm{mm}$ with thick of the walls equals $0.5 \mathrm{~mm}$. A maximum number of three complete hexagons has been positioned in the transverse direction of specimens; the corresponding number in the principal longitudinal direction is 22 . Therefore, the width is $23.67 \mathrm{~mm}$. 

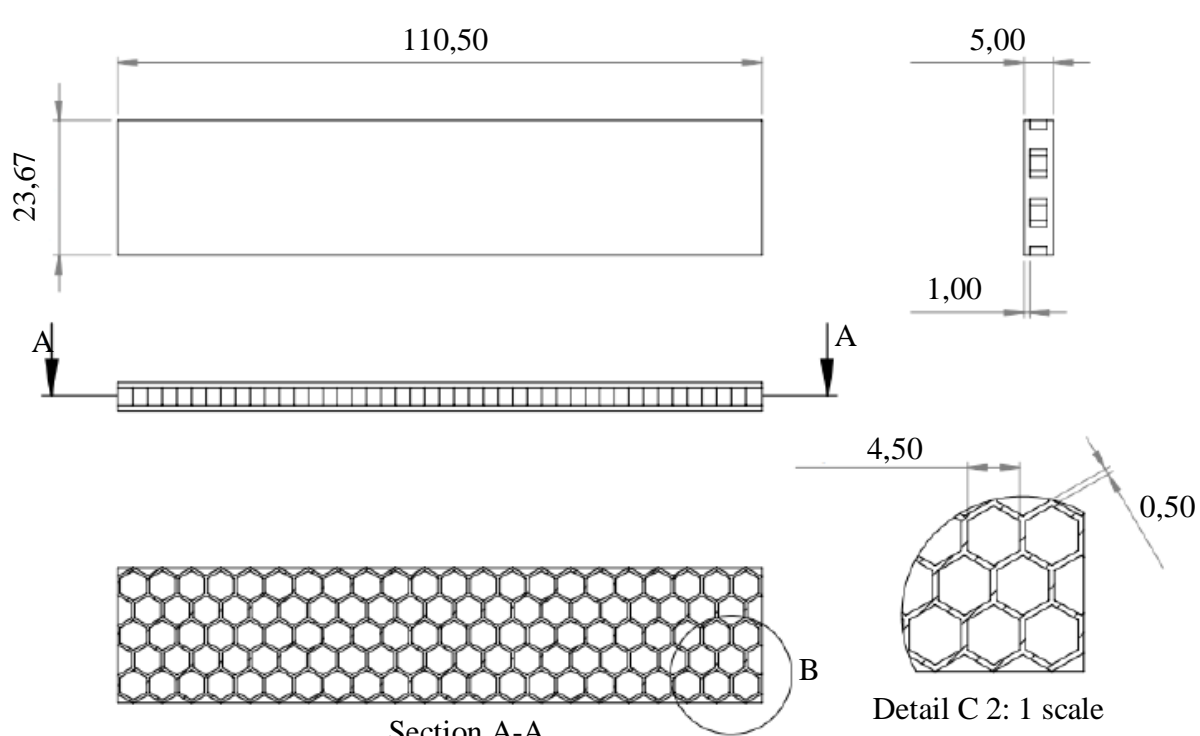

Section A-A

Detail C 2: 1 scale

Fig. 1: Geometrical data and lamination scheme of the 12 produced sandwich specimens

Table 1: Geometrical data and weight of the 12 printed sandwich specimens

\begin{tabular}{lllll}
\hline Specimen (family) & $\mathbf{Y}[\mathbf{m m}]$ & $\mathbf{Z}[\mathbf{m m}]$ & $\mathbf{X}[\mathbf{m m}]$ & $\mathbf{W}[\mathbf{g}]$ \\
\hline $1(1)$ & 23.67 & 5.06 & 110.71 & 9.52 \\
$2(1)$ & 23.62 & 5.09 & 110.74 & 9.49 \\
$3(1)$ & 23.64 & 5.00 & 110.61 & 9.42 \\
$4(1)$ & 23.67 & 5.02 & 110.67 & 9.46 \\
$5(1)$ & 23.65 & 5.08 & 110.68 & 9.49 \\
$6(1)$ & 23.70 & 5.03 & 110.70 & 9.47 \\
$7(2)$ & 23.69 & 5.04 & 110.64 & 9.45 \\
$8(2)$ & 23.68 & 5.06 & 110.71 & 9.46 \\
$9(2)$ & 23.65 & 5.05 & 110.68 & 9.42 \\
$10(2)$ & 23.63 & 5.02 & 110.66 & 9.50 \\
$11(2)$ & 23.67 & 5.05 & 110.73 & 9.50 \\
$12(2)$ & 23.66 & 5.07 & 110.69 & 9.50 \\
TARGET & $\mathbf{2 3 . 6 7}$ & $\mathbf{5 . 0 0}$ & $\mathbf{1 1 0 . 5 0}$ & $\mathbf{8 . 4 9}$ \\
\hline
\end{tabular}

After the production of 12 specimens, their dimensions have been measured by means of a digital caliper while the entire weight has been defined using a digital precision weight scale. These data have been collected in Table 1 . The specimens have been grouped in two families as the production consisted in two different runs: the first six specimens have been printed before the other six ones. The width of each specimen in millimeters is indicated in the second column as $\mathrm{Y}$. The thickness is called as $\mathrm{Z}$ and it is given in the third column in millimeters. The length is indicated in millimeters as $\mathrm{X}$ in the fourth column. The weight $\mathrm{W}$ is indicated in grams in the last column. The last row of Table 1 gives the target values for each of the 4 geometrical parameters. The geometrical dimensions $(\mathrm{Y}$, $\mathrm{Z}$ and $\mathrm{X}$ ) are those reported in Fig. 1, they correspond to the 3D CAD quotes of the specimens. The target weight was obtained multiplying the volume of the specimen (that is its overall footprint, minus the empty spaces in the honeycomb core, automatically calculated by the CAD software) and the mass density of the PLA filament. This operation was made under the assumption of $100 \%$ infill for the external skins.

\section{Capability Analysis for Dimensional Parameters}

In this capability analysis, the first step is to understand if the collected data can be represented by a normal distribution. In Table 2 and Figs. 2 to 5, this information is provided by means of two indexes that are the Anderson Darling value (AD-value) and the Probability value (P-value). A low value for $\mathrm{AD}$ means that the given data can be successfully represented by the proposed normal distribution, this information is further confirmed by an high value for the P-index (it goes from 0 to 1 and it must be usually greater than a treshold value equals 0.05 ). The normality test has been passed by all the three dimensions $\mathrm{Y}, \mathrm{Z}$ and $\mathrm{X}$ and also by the weight $\mathrm{W}$ (see the images in Figs. 2 to 5 and the AD-values and P-values shown for all the 12 specimens collected in Table 2). 


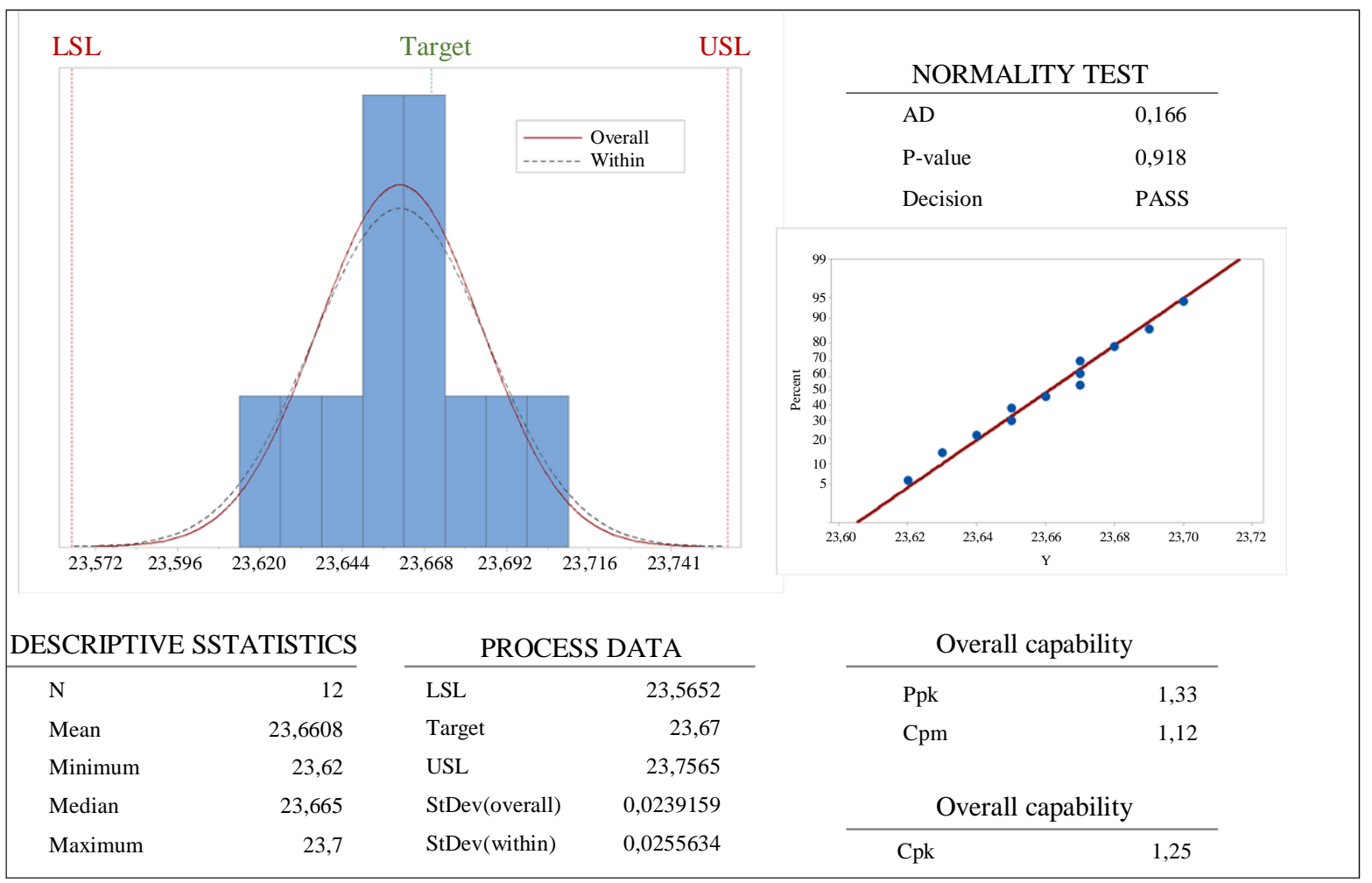

Fig. 2: Graphical summary, probability plot and process capability report for the dimension Y of the 12 produced sandwich specimens

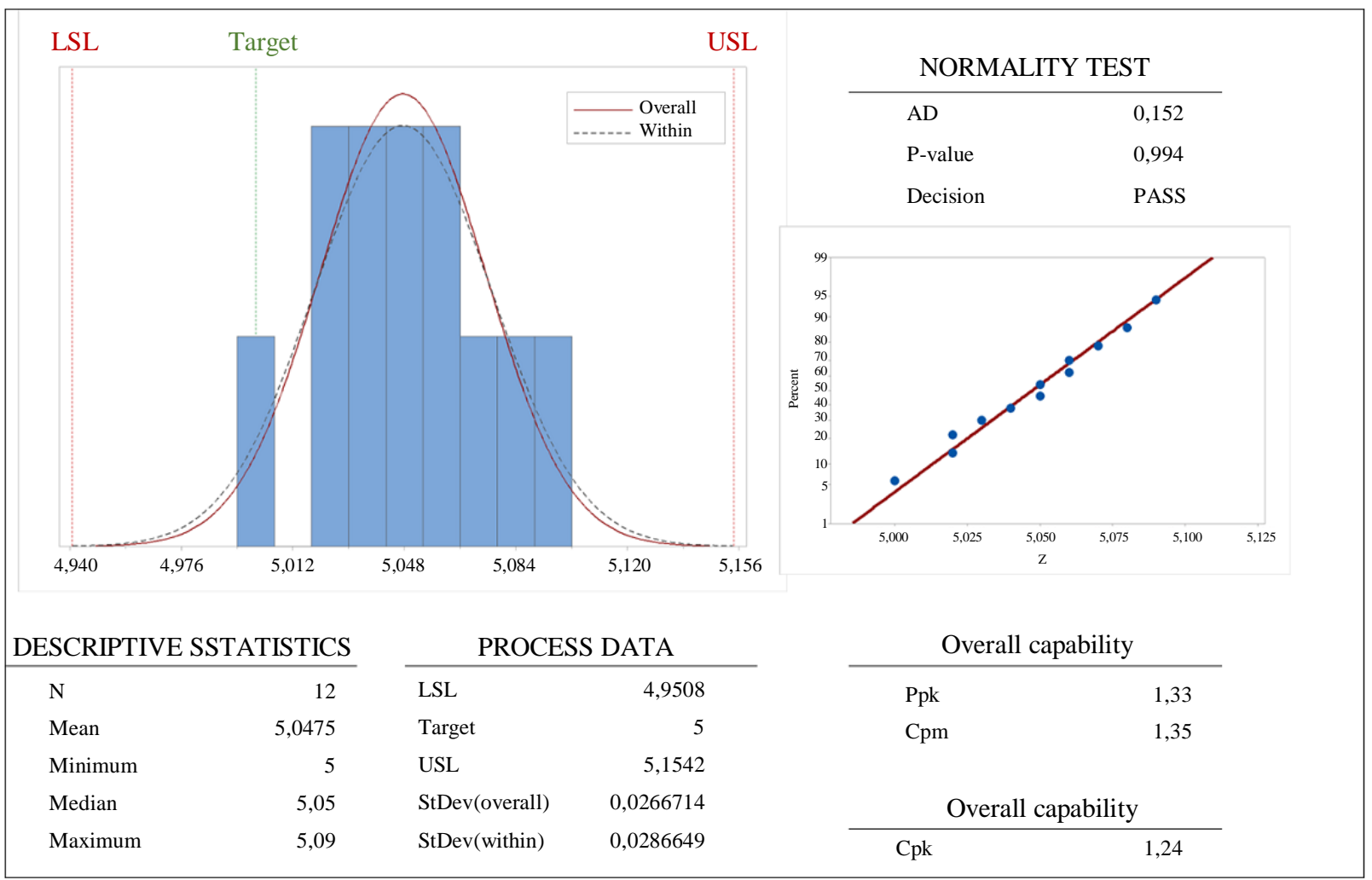

Fig. 3: Graphical summary, probability plot and process capability report for the dimension $\mathrm{Z}$ of the 12 produced sandwich specimens 
Salvatore Brischetto and Roberto Torre / Journal of Aircraft and Spacecraft Technology 2020, Volume 4: 54.69 DOI: 10.3844/jastsp.2020.54.69

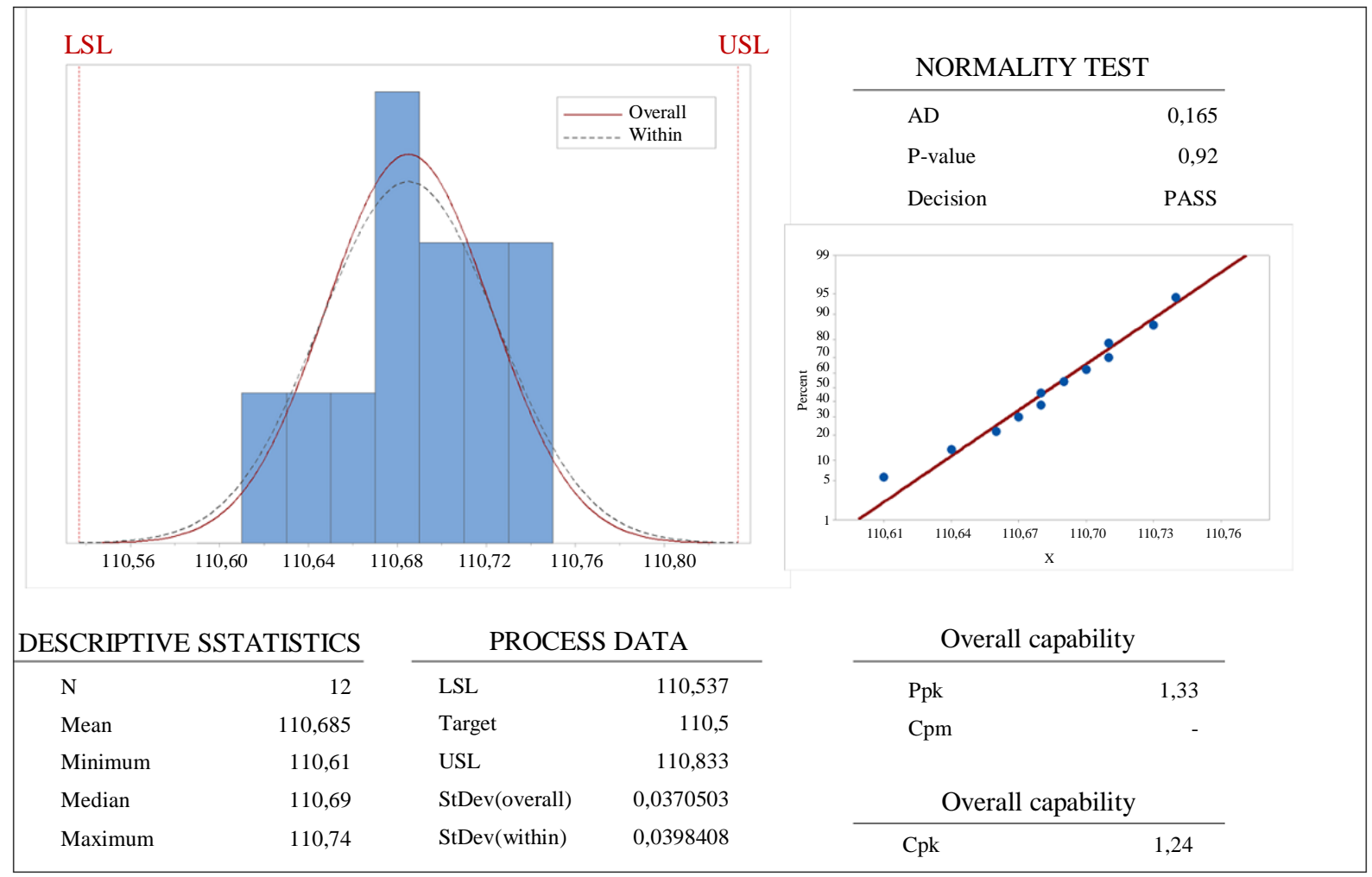

Fig. 4: Graphical summary, probability plot and process capability report for the dimension $\mathrm{X}$ of the 12 produced sandwich specimens

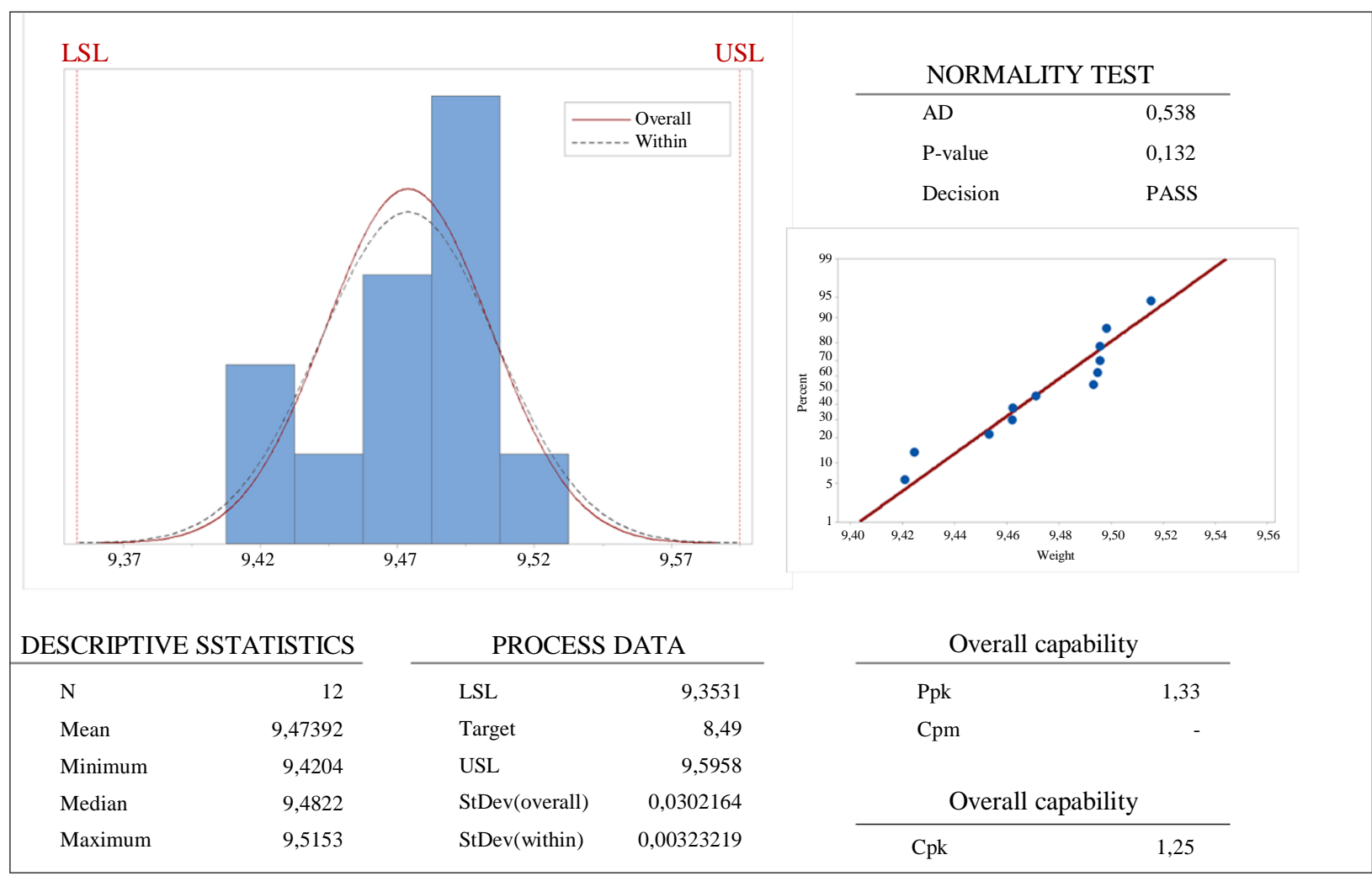

Fig. 5: Graphical summary, probability plot and process capability report for the weight $\mathrm{W}$ of the 12 produced sandwich specimens 
Salvatore Brischetto and Roberto Torre / Journal of Aircraft and Spacecraft Technology 2020, Volume 4: 54.69 DOI: 10.3844/jastsp.2020.54.69

Table 2: Summary of the capability analysis for the dimensions and weight of the produced sandwich specimens

\begin{tabular}{lcccc}
\hline All the 12 specimens & Y & Z & X & W \\
\hline Mean value $\mu$ & 23.6608 & 5.0475 & 110.685 & 9.4739 \\
Stand. dev. $\hat{\sigma}$ & 0.02392 & 0.02667 & 0.03705 & 0.03022 \\
LSL & 23.5652 & 4.9408 & 110.537 & 9.3531 \\
USL & 23.7565 & 5.1542 & 110.833 & 9.5948 \\
AD-value & 0.166 & 0.152 & 0.165 & 0.538 \\
P-value & 0.918 & 0.944 & 0.920 & 0.132 \\
& The first six specimens of the family 1 & & \\
Mean value $\mu$ & 23.6583 & 5.0467 & 110.685 & 9.4769 \\
Stand. dev. $\hat{\sigma}$ & 0.02787 & 0.03559 & 0.04416 & 0.03180 \\
& The second six specimens of the family 2 & & \\
Mean value $\mu$ & 23.6633 & 5.0483 & 110.685 & 9.4710 \\
Stand. dev. $\hat{\sigma}$ & 0.02160 & 0.01722 & 0.03271 & 0.03125 \\
\hline
\end{tabular}

Therefore, by using the normal distribution, a mean value $\mu$ and a standard deviation $\hat{\sigma}$ can be calculated. The 12 specimens were printed in two different runs, the evaluation of mean values and standard deviations can be done following two different approaches: when all the 12 specimens are considered, by ignoring the separation in families, the statistical indices are calculated for a socalled "long period". The name is due to the fact that measurements are collected for processes separately occurred in time, by taking into account the "overall" capability of the process. On the contrary, the statistical indices calculated for a single run (which means a single "family") take into account the "within" capability of the process, defined, in this case, in the so-called "short period". The capability of a process depends on the sources of variation that could modify its stability. Processes are usually less stable in the long period because in a longer time (which means for different runs) it easier for the sources of variation to manifest themselves. However, the reader could find a different scenario in some parts of Table 2 and in Figs. 2-4: the standard deviations and consequently the process variations, assume similar values among the short and the long period. In particular, the overall process seems to be more stable. The main reason lies in the reduced number of employed specimens and in the small size of specimens which give statistical indices inappropriate for the process. After the determination of the mean value $m$ and the standard deviation $\hat{\sigma}$, a range between an Upper Specification Limit (USL) and a Lower Specification Limit (LSL) is calculated. In the present case, a $\hat{\sigma}$-level equals 4 has been adopted and USL $=\mu$ $+4 \hat{\sigma}$ and LSL $=\mu-4 \hat{\sigma}$. This feature means that the $99.38 \%$ of the next produced specimens should have geometrical dimensions and weights inside the range with limits given by the USL and the LSL.

The width $\mathrm{Y}$ has a mean value equals $23.6608 \mathrm{~mm}$ with standard deviation equals $0.02392 \mathrm{~mm}$. By imposing $\hat{\sigma}$ - level equals 4 , the USL is $23.7565 \mathrm{~mm}$ and the LSL is $23.5652 \mathrm{~mm}$. As shown in Fig. 1 and in
Table 1, the target value for $\mathrm{Y}$ dimension is $23.67 \mathrm{~mm}$. This value falls inside the calculated LSL-USL range and it is very close to process mean value. The difference between the two values in percentage is about $-0.04 \%$.

The thickness $X$ has a mean value equals $5.0475 \mathrm{~mm}$ with standard deviation equals $0.02667 \mathrm{~mm}$. By imposing $\hat{\sigma}$-level equals 4 , the USL is $5.1542 \mathrm{~mm}$ and the LSL is $4.9408 \mathrm{~mm}$. From Table 1 and Fig. 1, the target $\mathrm{X}$ dimension is $5 \mathrm{~mm}$. It gives a difference in percentage (calculated with respect to the mean value) equals $+0.95 \%$. This value, with the modified algebraic sign, could be used as a correction factor to re-scale the dimension in the longitudinal direction.

The length $Z$ has a mean value equals $110.685 \mathrm{~mm}$ with standard deviation equals $0.03705 \mathrm{~mm}$. By imposing $\hat{\sigma}$-level equals 4 , the USL is $110.833 \mathrm{~mm}$ and the LSL is $110.537 \mathrm{~mm}$. In Fig. 1 and Table 1 the $\mathrm{Z}$ dimension has a target value equals $110.5 \mathrm{~mm}$. The difference in percentage (with respect to the mean value) is $+0.30 \%$. This difference (using the modified algebraic sign) can be used to obtain actual dimensions closer to the mean value.

The weight $\mathrm{W}$ has a mean value equals $9.4739 \mathrm{~g}$ with standard deviation equals $0.03022 \mathrm{~g}$. By imposing $\hat{\sigma}$-level equals 4 , the USL is $9.5948 \mathrm{~g}$ and the LSL is $9.3531 \mathrm{~g}$. The target value for $\mathrm{W}$ is $8.49 \mathrm{~g}$ and it is completely outside the range and very far from the mean value. In this case, the weight is not a direct parameter but it derives from the dimensional data and from the parameters chosen for the printing process. On average, the specimens are $11.6 \%$ heavier than the expected value. A reduction of this gap could be obtained via the proposed adjustments for the geometrical dimensions already proposed. Moreover, the printer could have an over-extrusion in the interior portions of the specimens and these features cannot be measured. An example is the thickness of the hexagon walls, which cannot be measured (because they are inside the specimens) and they are very close to the inplane resolution of the printer. 
The conducted analysis allows to evaluate the printing process and also to investigate possible modifications to improve the quality of future produced sandwich specimens.

\section{Experimental Bending Tests on Sandwich Specimens}

The test was performed in accordance with the procedure given in the ASTM D790 standard (ASTM, 2017a). The thickness and the width of each specimen was already measured in the previous sections where the collected results have been used to test the process performances and also to have the geometrical characteristics to calculate the mechanical properties in this section. These geometrical data are summarized in Table 1.

The experimental test set-up is possible after the evaluation of the geometrical characteristics. Each produced specimen was positioned horizontally in a resting position over two supports. The load was applied by means of a vertical nose, acting on the upper surface and symmetrically positioned between the resting supports. This test is named as Type I as suggested in the ASTM D790 standard (ASTM, 2017a). While the load was applied, the deflection of the specimen was measured by the cross-head position. The motion of the cross-head was set at a constant strain rate $\mathrm{S}$ for the external fibers equals $0.01 \mathrm{~mm} / \mathrm{mm} / \mathrm{min}$. The rate of the cross-head motion was then calculated as:

$R=\frac{S L^{2}}{6 d}$

where, $L$ is the distance between the two supports of the testing machine, its value is $90 \mathrm{~mm}$. $d$ is the thickness of each tested specimen. The result obtained from Equation (1) was imposed as testing speeds. $R$ was therefore expressed as $[\mathrm{mm} / \mathrm{min}]$.

As suggested in the ASTM D790 standard (ASTM, 2017a), the test is concluded when the strain of the outer fibers equals $0.05 \mathrm{~mm} / \mathrm{mm}$. The control parameter for the testing machine is the deflection $D$, its limit is calculated as:

$D=\frac{r L^{2}}{6 d}$

$D$ is given in [mm], $r$ is the strain of the outer fibers and it was set equal to the reference value. $L$ and $d$ have been already described for the previous equation.

The output data from the experimental testing machine during the conducted tests are the deflection $D$ and the load $P$ at the considered point. In order to obtain the typical stress-strain curves, the flexural stress $\sigma_{f}$ and the flexural strain $\varepsilon_{f}$ were opportunely defined.

The flexural stress is defined as the maximum stress produced in the specimen for a certain load. After the setting of the geometry, boundary conditions and the load configuration, the maximum stress experimented at the outer surface (in the midpoint) is defined as:

$\sigma_{f}=\frac{3 P L}{2 b d^{2}}$

where, $P$ is the load at the considered point and it is given in $[\mathrm{N}] . b$ is the width of the considered specimen. $L$ and $d$ have been discussed for the previous equations.

The flexural strain is defined as the strain of the outer surface in the midpoint, where its maximum value is obtained. It was defined as:

$\varepsilon_{f}=\frac{6 D d}{L^{2}}$,

By using the definitions given in Equation (3) and (4), it is possible to produce the typical stress-strain curves for the three-point bending tests of the printed sandwich specimens. Results for family 1 are given in Fig. 6 and those for family 2 are in Fig. 7. For each graph plotted for a single specimen, it is possible to define the following typical flexural mechanical properties.

The maximum flexural strength $\sigma_{\max }$ in $[\mathrm{MPa}]$ is defined as the maximum value of the flexural stress which can be sustained by the specimen.

The linear elastic bending Young modulus $E_{\text {lin }}$ in [MPa] indicates the material resistance to deformation under stress. From a graphical point of view, it indicates the slope of the stress-strain curve at a certain stress level. It can be noticed that all the specimens showed an initial Hookean behavior. Therefore, in this part of the graph, the trend of the stress-stain curve is almost linear. The stress level corresponding to a change in the slope of the curve was identified. Defining as $N_{s}$ this $N$-th point, a Matlab tool was implemented to build $N_{s}-1$ ranges of values. The $N$-th range contains all the values included between the first one and the $N-1$ point. Then, a linear regression, based on each of these ranges, can be performed. Finally, these coefficients were averaged.

In each image of Figs. 6 and 7, calculated flexural strength $\sigma_{\max }$ and linear elastic bending Young modulus $E_{\text {lin }}$ are clearly indicated. Then, they are also summarized in Table 3 where the family is indicated for each of the 12 specimens; the maximum flexural stress and the linear elastic bending Young modulus values are given in the last two columns. These 12 values for each mechanical property will be used in the next section for the capability analysis. 

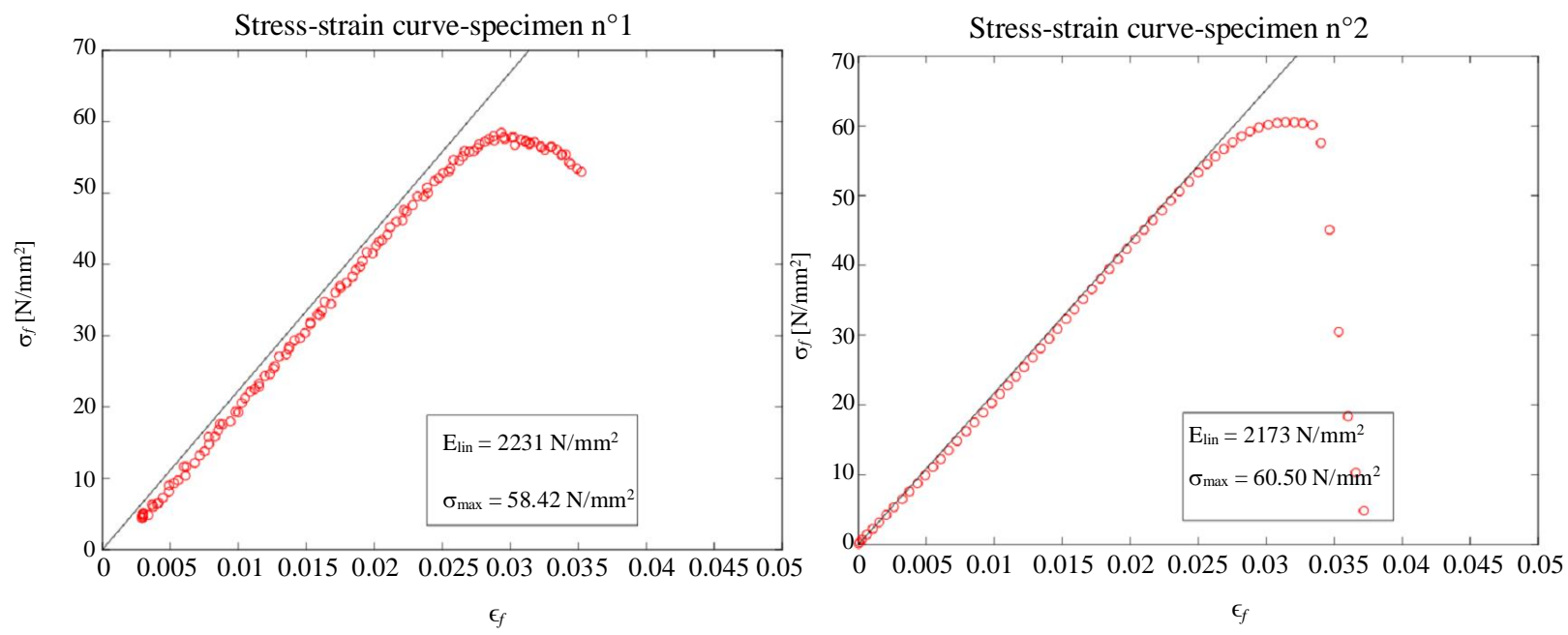

Stress-strain curve-specimen $n^{\circ} 3$
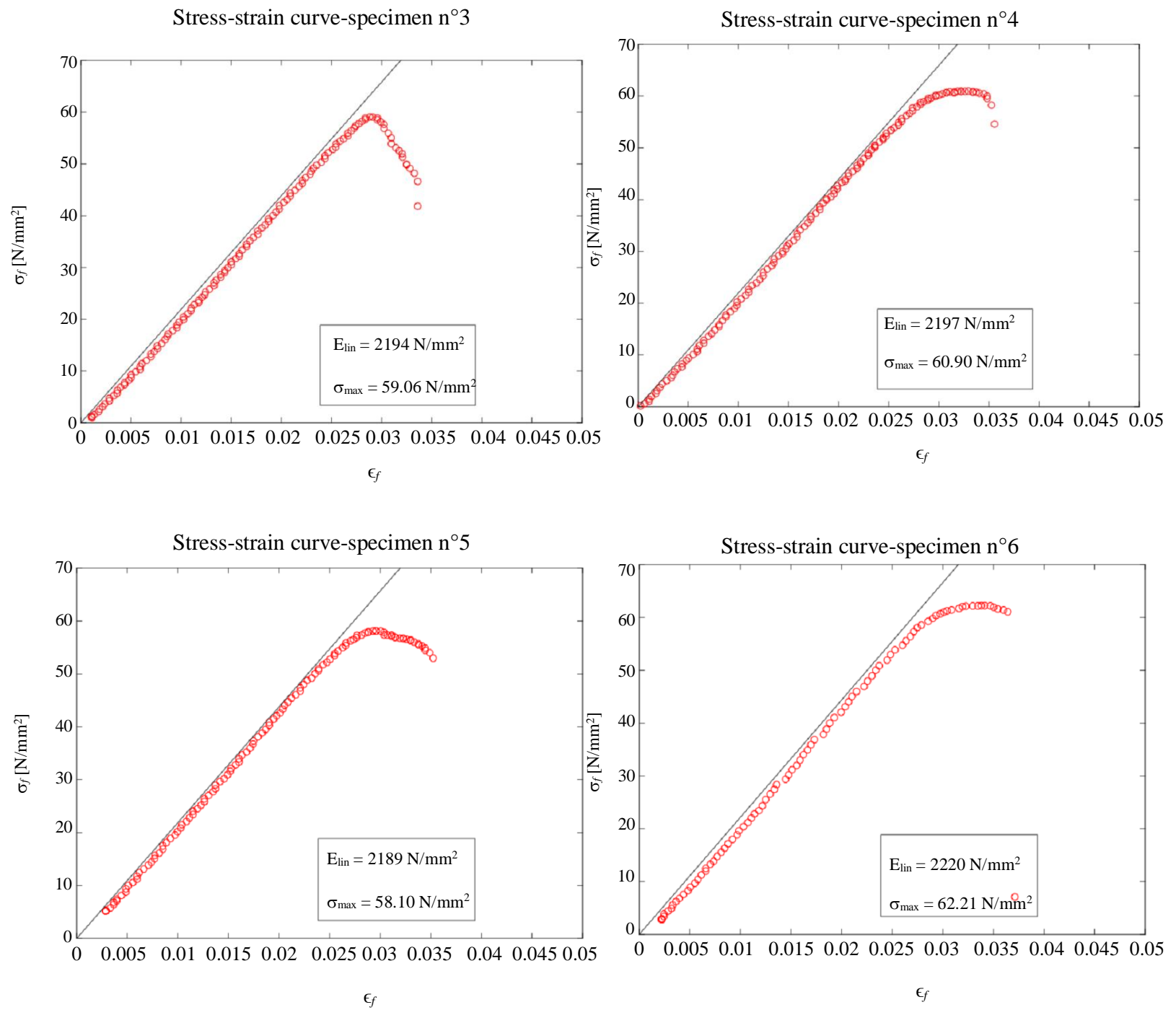

Fig. 6: Stress-strain curves for the three-point bending tests of the first six sandwich specimens of the family 1 


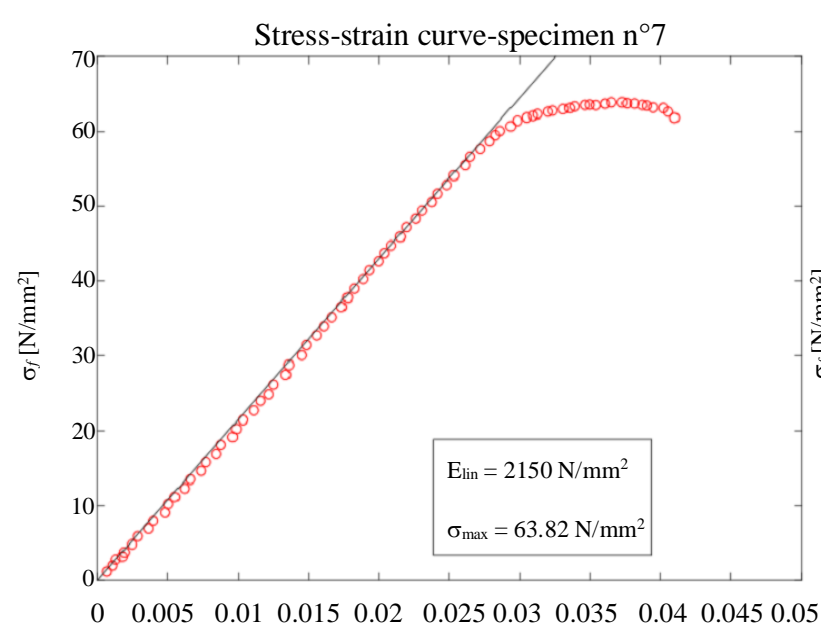

$\epsilon_{f}$

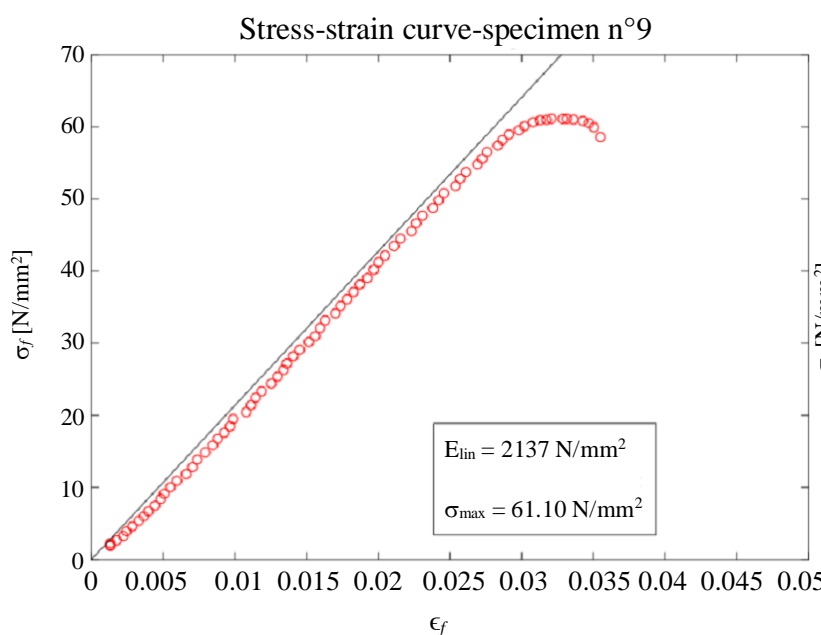

$\epsilon_{f}$

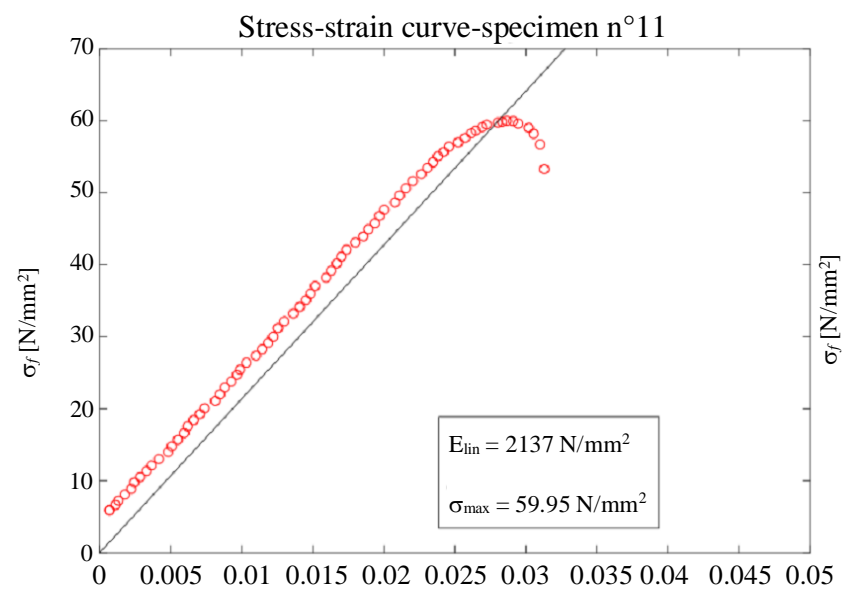

$\epsilon_{f}$

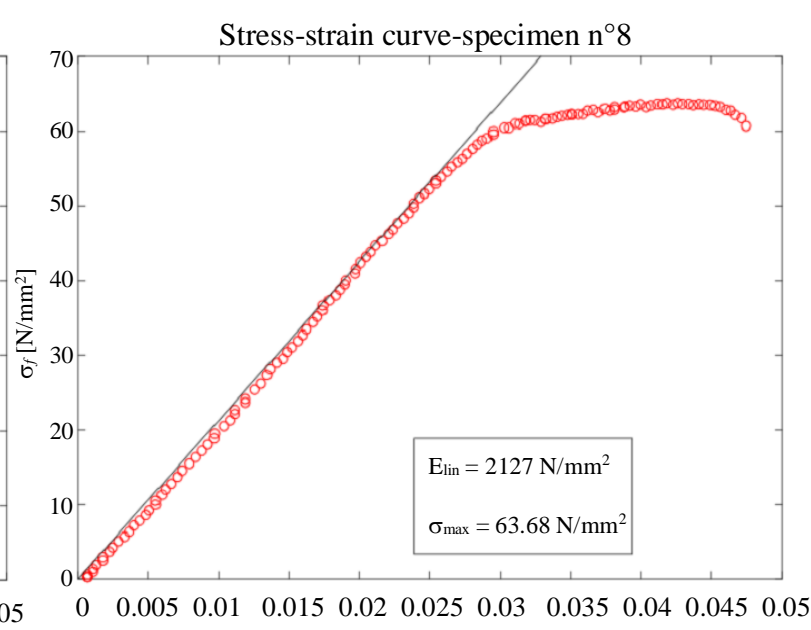

$\epsilon_{f}$
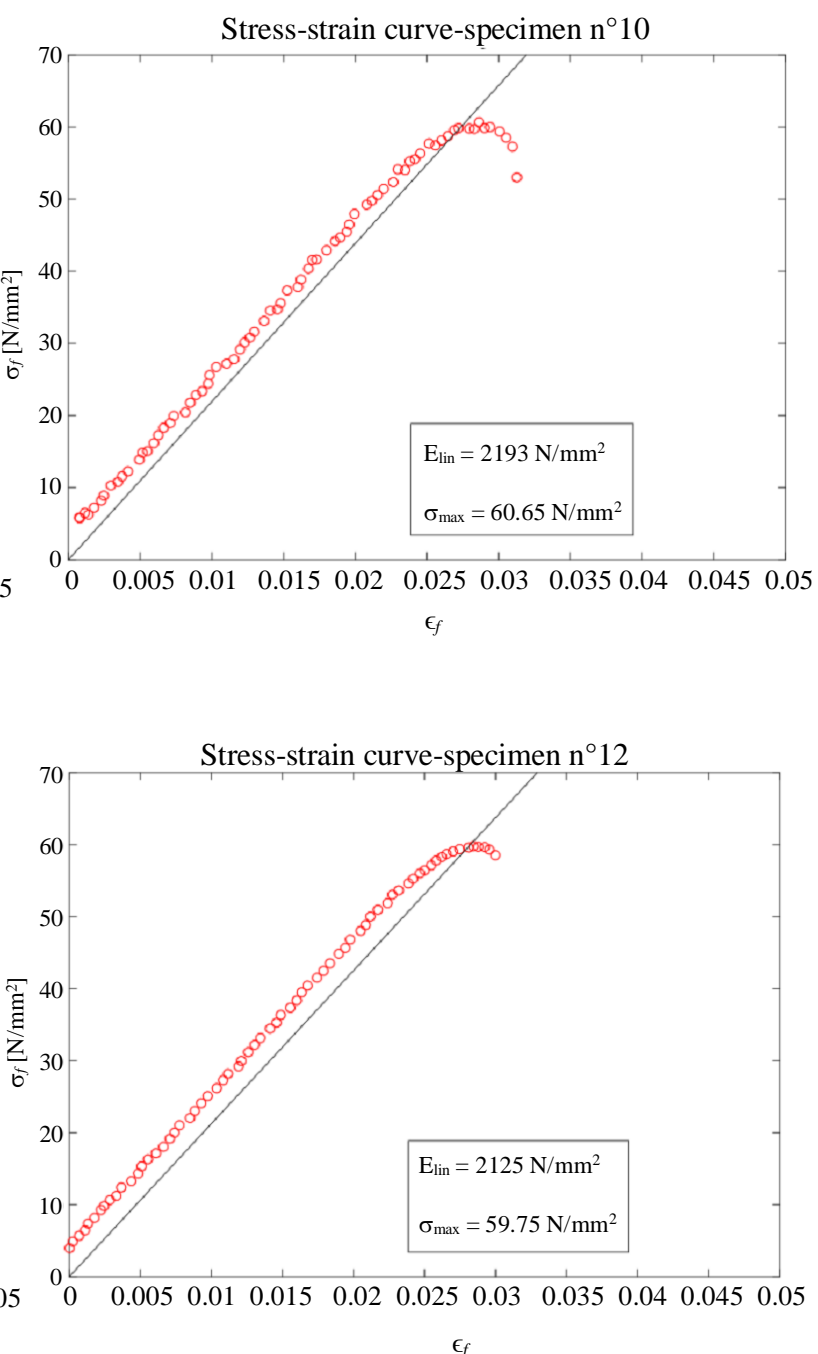

$\epsilon_{f}$

Fig. 7: Stress-strain curves for the three-point bending tests of the second six sandwich specimens of the family 2 
Table 3: Linear elastic bending Young modulus $E_{\text {lin }}$ and maximum flexural stress $\sigma_{\max }$ of the 12 printed sandwich specimens

\begin{tabular}{lll}
\hline Specimen (family) & $\boldsymbol{E}_{\text {lin }}[\mathbf{M P a}]$ & $\boldsymbol{\sigma}_{\max }[\mathbf{M P a}]$ \\
\hline $1(1)$ & 2231.2 & 58.4 \\
$2(1)$ & 2172.7 & 60.5 \\
$3(1)$ & 2193.6 & 59.1 \\
$4(1)$ & 2197.0 & 60.9 \\
$5(1)$ & 2189.4 & 58.1 \\
$6(1)$ & 2219.8 & 62.2 \\
$7(2)$ & 2150.2 & 63.8 \\
$8(2)$ & 2127.1 & 63.7 \\
$9(2)$ & 2136.5 & 61.1 \\
$10(2)$ & 2193.0 & 60.6 \\
$11(2)$ & 2137.1 & 59.9 \\
$12(2)$ & 2125.3 & 59.8
\end{tabular}

\section{Capability Analysis for Mechanical Properties}

As already seen for the geometrical data, the first step of the capability analysis is to understand if the collected data can be represented by a normal distribution. In Table 4 and in Figs. 8 and 9, this information is given by means of two indexes that are the Anderson Darling value (AD-value) and the Probability value (P-value). The guidelines are the same already given in the previous section: the sample of data can be successfully represented by a normal distribution when a low value for $\mathrm{AD}$ is obtained; moreover, an high value for the P-value further confirms this feature. Both the linear elastic bending Young modulus $E_{\text {lin }}$ and the maximum flexural strength $\sigma_{\max }$ passed the normality test (see the images in Figs. 8 and 9 and the AD-value and P-value shown for all the 12 specimens collected in Table 4). Even if the AD-value for both the mechanical properties is not so low, the P-value is however sufficiently higher than the threshold value. Therefore, by using the normal distribution, a mean value $\mu$ and a standard deviation $\hat{\sigma}$ can be calculated. This step can be performed for all the 12 specimens and it is an overall capability analysis carried out in the long period. However, it can be also performed for each family composed by 6 specimens and in this case it is a potential or within capability analysis carried out in the short period. A process is usually more stable in the short period with respect to the long period, this conclusion is confirmed for both the mechanical variables as shown in the images of Figs. 8 and 9 (see collected values for standard deviation $\hat{\sigma}, C_{p}$ and $P_{p}$ proposed in the related tables and figures). After the determination of the mean values and the standard deviations, a range between an Upper Specification Limit (USL) and a Lower Specification Limit (LSL) is calculated. In the present case, a $\hat{\sigma}$-level equals 4 has been adopted: $\mathrm{USL}=\mu+4 \hat{\sigma}$ and $\mathrm{LSL}=$ $\mu-4 \hat{\sigma}$. This feature means that the $99.38 \%$ of the next produced specimens should have linear elastic bending
Young modulus $E_{\text {lin }}$ and maximum flexural strength $\sigma_{\max }$ inside the range with limits given by the USL and the LSL. The main difference with respect to the capability analysis performed for the geometrical data is the absence of any target or nominal value for the case of mechanical properties.

The linear elastic bending Young modulus $E_{\text {lin }}$ has a mean value equals $2172.74 \mathrm{MPa}$ with standard deviation equals 36.6421 MPa. By imposing $\hat{\sigma}$-level equals 4 , the USL is $2319.31 \mathrm{MPa}$ and the LSL is 2026.17 MPa. In the case of this mechanical property, there is not any target or nominal value. However, we can use the USL and the LSL in a conservative way in order to select opportune design values. For example, in the case of a future static bending analysis of a structural element made of the same PLA and produced with the same technology and the same printing parameters, the employed value (to be more conservative as possible) could be the LSL $=2026.17$ $\mathrm{MPa}$ because the $99.38 \%$ of the future produced elements will have a linear elastic bending Young modulus $E_{\text {lin }}$ greater than the LSL.

The maximum flexural strenght $\sigma_{\max }$ has a mean value equals $60.6750 \mathrm{MPa}$ with standard deviation equals $1.8380 \mathrm{MPa}$. By imposing $\hat{\sigma}$-level equals 4 , the USL is $68.0272 \mathrm{MPa}$ and the LSL is $53.3228 \mathrm{MPa}$. In the case of this mechanical property, there is not any target or nominal value. However, we can use the USL and the LSL in a conservative way in order to select opportune design values. For example, in the case of a future static bending analysis of a structural element made of the same PLA and produced with the same technology and the same printing parameters, the employed value (to be more conservative as possible in the case of a verification of strength) could be $53.3228 \mathrm{MPa}$ because if we use it in the verification $\sigma_{l}$ $\leq S F \times L S L$ (where $\sigma_{1}$ is the contingent stress and SF is the Safety Factor), the $99.38 \%$ of the future produced elements will satisfy this relation having a maximum flexural strength $\sigma_{\max }$ greater than the LSL in the $99.38 \%$ of the cases. 


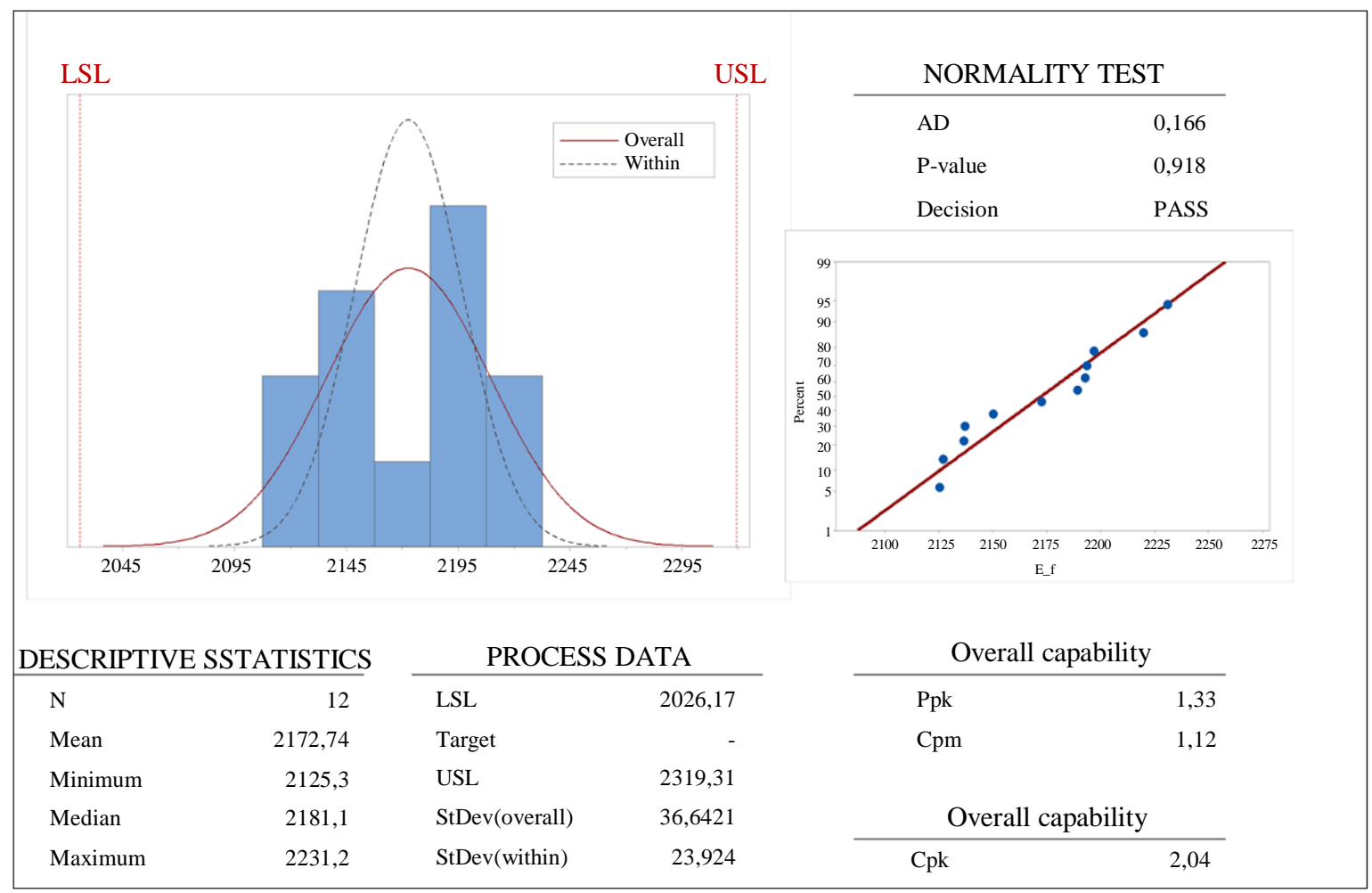

Fig. 8: Graphical summary, probability plot and process capability report for the linear elastic bending Young modulus $E_{\text {lin }}$ of the 12 produced sandwich specimens

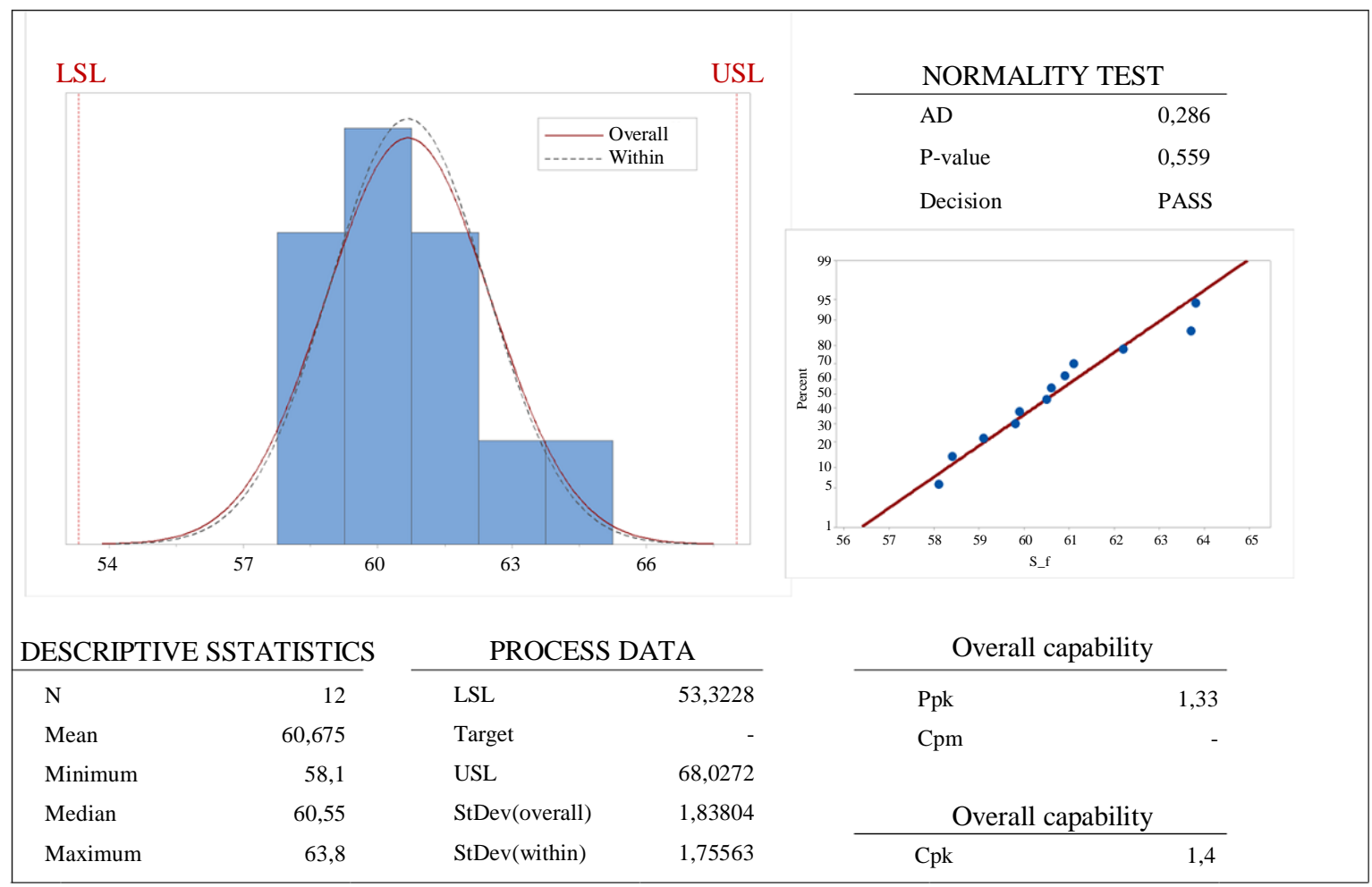

Fig. 9: Graphical summary, probability plot and process capability report for the maximum flexural stress $\sigma_{\max }$ of the produced 12 sandwich specimens 
Table 4: Summary of the capability analysis for the linear elastic bending Young modulus $E_{\text {lin }}$ and maximum flexural stress $\sigma_{\max }$ of the produced sandwich specimens

\begin{tabular}{|c|c|c|}
\hline All the 12 specimens & $\boldsymbol{E}_{\text {lin }}$ & $\sigma_{\max }$ \\
\hline Mean value $\mu$ & 2172.74 & 60.6750 \\
\hline Stand. dev. $\hat{\sigma}$ & 36.6421 & 1.8380 \\
\hline LSL & 2026.17 & 53.3228 \\
\hline USL & 2319.31 & 68.0272 \\
\hline AD-value & 0.421 & 0.286 \\
\hline P-value & 0.271 & 0.559 \\
\hline \multicolumn{3}{|c|}{ The first six specimens of the family 1} \\
\hline Mean value $\mu$ & 2200.62 & 59.8667 \\
\hline Stand. dev. $\hat{\sigma}$ & 21.3111 & 1.5983 \\
\hline \multicolumn{3}{|c|}{ The second six specimens of the family 2} \\
\hline Mean value $\mu$ & 2144.87 & 61.4833 \\
\hline Stand. dev. $\hat{\sigma}$ & 25.1956 & 1.8192 \\
\hline
\end{tabular}

\section{Main Conclusion and Further Developments}

The paper proposes an experimental evaluation of the flexural properties of PLA sandwich specimens embedding two external homogeneous skins and an internal honeycomb core, these specimens have been produced by means of a desktop 3D printer based on the FDM technology. A capability analysis has been performed on the geometrical data and on the weight of the produced specimens in order to evaluate the production process and to propose future improvements in the printing of further sandwich specimens. A possible improve in the printing process can be obtained using the percentage deviations, from the nominal geometrical values, calculated in the present paper. After this study, these specimens have been experimentally tested by means of a three-point bending test in order to evaluate the linear elastic bending Young modulus $E_{\text {lin }}$ and the maximum flexural strength $\sigma_{\max }$. For both the mechanical properties, a capability analysis has been performed and a sigma level equals 4 has been imposed to determine a statistically stable range. The found results for the Young modulus $E_{\text {lin }}$ are mean value equals 2172.74 MPa with standard deviation equals 36.6421 $\mathrm{MPa}, \mathrm{USL}=2319.31 \mathrm{MPa}$ and LSL $=2026.17 \mathrm{MPa}$. The calculated results for the maximum flexural strength $\sigma_{\max }$ are mean value equals $60.6750 \mathrm{MPa}$ with standard deviation equals $1.8380 \mathrm{MPa}$, USL $=68.0272 \mathrm{MPa}$ and LSL $=53.3228 \mathrm{MPa}$. For both the mechanical properties, the USL and LSL can be used with confidence in structural analyses in a conservative way as indicated in the section about results.

New configurations will be tested in the future in order to evaluate different polymeric materials other than PLA and different core types other than the honeycomb one. Moreover, further experimental tests (other than the bending static analysis) will be conducted to obtain more complete data about the mechanical behavior of sandwich specimens produced via the 3D FDM printing process.

\section{Acknowledgement}

Some of the experimental tests were conducted within the course "Design and additive manufacturing for aerospace applications".

\section{Author's Contributions}

The authors contributed equally to this work.

\section{Ethics}

This article is original and contains unpublished material. The corresponding author confirms that all of the other authors have read and approved the manuscript and no ethical issues involved.

\section{References}

ASTM, 2017a. Standard Test Methods for Flexural Properties of Unreinforced and Reinforced Plastics and Electrical Insulating Materials. 1st Edn., Annual Book of ASTM Standards, ASTM International, West Conshohocken, PA, USA.

ASTM, 2017b. Standard Test Methods for Flexural Properties of Unreinforced and Reinforced Plastics and Electrical Insulating Materials by Four-Point Bending. 1st Edn., Annual Book of ASTM Standards, ASTM International, West Conshohocken, PA, USA.

Bici, M., S. Brischetto, F. Campana, C.G. Ferro and C. Secli et al., 2018. Development of a multifunctional panel for aerospace use through SLM additive manufacturing. Proceedings of the 11 th CIRP Conference on Intelligent Computation in Manufacturing Engineering, Jul. 17-17, Elsevier, Ischia, Italy, pp: 215-220. DOI: 10.1016/j.procir.2017.12.202

Brischetto, S., A. Ciano and A. Raviola, 2015. Patent application "Multipurpose modular drone with adjustable arms" number 102015000069620. Filing Date of Patent Application.

Brischetto, S., A. Ciano and C.G. Ferro, 2016a. A multipurpose modular drone with adjustable arms produced via the FDM additive manufacturing process. Curved Layered Structures, 3: 202-213. DOI: $10.1515 / \mathrm{cls}-2016-0016$

Brischetto, S., C.G. Ferro, R. Torre and P. Maggiore, 2016b. Tensile and compression characterization of 3D printed ABS specimens for UAV applications. Proceedings of the 3rd International Conference on Mechanical Properties of Materials, Dec. 14-17, Venice, Italy. 
Brischetto, S., C.G. Ferro, P. Maggiore and R. Torre, 2017a. Characterization and analysis of homogeneous and sandwich PLA/ABS specimens produced via the FDM printing process for UAV structural elements. Proceedings of the Mechcomp 3 - 3rd International Conference of Mechanics of Composites, Jul. 4-7, Bologna, Italy.

Brischetto, S., C.G. Ferro, P. Maggiore and R. Torre, 2017b. Compression tests of ABS specimens for UAV components produced via the FDM technique. Technologies, 5: 1-25.

DOI: 10.3390/technologies5020020

Brischetto, S., P. Maggiore and C.G. Ferro, 2017c. Additive Manufacturing Technologies and Applications. 1st Edn., MDPI AG, Basel, Switzerland, ISBN-13: 978-3-03842-548-9, pp: 180.

Brischetto, S., P. Maggiore and C.G. Ferro, 2017d. Editorial for the Special Issue on "Additive manufacturing technologies and applications. Technologies, 5: 1-2.

DOI: 10.3390/technologies5030058

Brischetto, S., C.G. Ferro, R. Torre and P. Maggiore, 2018. 3D FDM production and mechanical behavior of polymeric sandwich specimens embedding classical and honeycomb cores. Curved Layered Structures, 5: 80-94.

DOI: $10.1515 / \mathrm{cls}-2018-0007$

Brischetto, S., R. Torre and C.G. Ferro, 2020. Experimental evaluation of mechanical properties and machine process in fused deposition modelling printed polymeric elements. Proceedings of the International Conference on Additive Manufacturing, Modeling Systems and 3D Prototyping, Jul. 24-28, Washington D.C., USA, pp: 377-389. Springer. DOI: 10.1007/978-3-030-20216-3

Carlier, E., S. Marquette, C. Peerboom, L. Denis and S. Benali et al., 2019. Investigation of the parameters used in fused deposition modeling of poly (lactic acid) to optimize 3D printing sessions. Int. J. Pharm., 565: 367-377. DOI: 10.1016/j.ijpharm.2019.05.008

Dana, H.R., F. Barbe, L. Delbreilh, M.B. Azzouna and A. Guillet et al., 2019. Polymer additive manufacturing of ABS structure: Influence of printing direction on mechanical properties. J. Manufact. Proc., 44: 288-298. DOI: 10.1016/j.jmapro.2019.06.015

Dizon, J.R.C., A.H. Espera Jr, Q. Chen and R.C. Advincula, 2018. Mechanical characterization of 3D-printed polymers. Additive Manufact., 20: 44-67. DOI: 10.1016/j.addma.2017.12.002

Duty, C., C. Ajinjeru, V. Kishore, B. Compton and N. Hmeidat et al., 2018. What makes a material printable? A viscoelastic model for extrusion-based 3D printing of polymers. J. Manufact. Proc., 35: 526-537. DOI: 10.1016/j.jmapro.2018.08.008
El Moumen, A., M. Tarfaoui and K. Lafdi, 2019. Additive manufacturing of polymer composites: Processing and modeling approaches. Comp. Part B, 171: 166-182. DOI: 10.1016/j.compositesb.2019.04.029

Ferro, C.G., S. Brischetto, P. Maggiore and R. Torre, 2017a. Multi-material sandwich panel produced with desktop 3D Printer. Proceedings of the Mechcomp 3 - 3rd International Conference of Mechanics of Composites, Jul. 4-7, Bologna, Italy.

Ferro, C.G., A.E.M. Casini, A. Mazza, P. Maggiore and S. Brischetto, 2017b. A novel design approach for space components: Application to a multifunctional panel. Proceedings of the 68th International Astronautical Congress, Sept. 25-29, Adelaide, Australia.

Ferro, C.G., S. Varetti, S. Brischetto and P. Maggiore, 2017c. Mechanical behaviour of a multifunctional panel for de-icing systems. Proceedings of the Mechcomp 3 - 3rd International Conference of Mechanics of Composites, Jul. 4-7, Bologna, Italy.

Ferro, C.G., S. Brischetto, G. Imbalzano, A. Mazza and P. Maggiore et al., 2018. Experimental tests and numerical evaluation of sandwich panels with trabecular core subjected to uniaxial compression, made by additive manufacturing. Proceedings of the International Conference on Composite Structures, Sept. 4-7, Bologna, Italy.

Ferro, C.G., S. Brischetto, R. Torre and P. Maggiore, 2016. Characterization of ABS specimens produced via the $3 \mathrm{D}$ printing technology for drone structural components. Curved Layered Structures, 3: 172-188. DOI: $10.1515 / \mathrm{cls}-2016-0014$

Gebisa, A.W. and H.G. Lemu, 2019. Influence of 3D printing FDM process parameters on tensile property of ULTEM 9085. Proceedings of the 14th Global Congress of Manufacturing and Management, (CMM' 19), ACM, pp: 331-338. DOI: 10.1016/j.promfg.2019.02.047

Harshitha, V. and S.S. Rao, 2019. Design and analysis of ISO standard bolt and nut in FDM 3D printer using PLA and ABS materials. Mater. Today: Proc., 19: 583-588. DOI: 10.1016/j.matpr.2019.07.737

Heidari-Rarani, M., M. Rafiee-Afarani and A.M. Zahedi, 2019. Mechanical characterization of FDM 3D printing of continuous carbon fiber reinforced PLA composites. Comp. Part B, 175: 107147.

DOI: 10.1016/j.compositesb.2019.107147

Lay, M., N.L.N. Thajudin, Z.A.A. Hamid, A. Rusli and M.K. Abdullah et al., 2019. Comparison of physical and mechanical properties of PLA, ABS and nylon 6 fabricated using fused deposition modeling and injection molding. Comp. Part B, 176: 107341. DOI: 10.1016/j.compositesb.2019.107341 
Levy, G.N., R. Schindel and J.P. Kruth, 2003. Rapid manufacturing and rapid tooling with Layer Manufacturing (LM) technologies, state of the art and future perspectives. CIRP Annals, 52: 589-609. DOI: 10.1016/S0007-8506(07)60206-6

Lu, B., D. Li and X. Tian, 2015. Development trends in additive manufacturing and 3D printing. Engineering, 1: 85-89. DOI: $10.15302 / \mathrm{J}-\mathrm{ENG}-2015012$

Mishra, P.K. and P. Senthil, 2020. Prediction of in-plane stiffness of multi-material 3D printed laminate parts fabricated by FDM process using CLT and its mechanical behaviour under tensile load. Mater. Today Commun., 23: 100955-100955.

DOI: $10.1016 /$ j.mtcomm.2020.100955

Parandoush, P. and D. Lin, 2017. A review on additive manufacturing of polymer-fiber composites. Comp. Structures, 182: 36-53.

DOI: 10.1016/j.compstruct.2017.08.088

Popescu, D., A. Zapciu, C. Amza, F. Baciu and R. Marinescu, 2018. FDM process parameters influence over the mechanical properties of polymer specimens: A review. Polymer Test., 69: 157-166. DOI: 10.1016/j.polymertesting.2018.05.020

Raj, S.A., E. Muthukumaran and K. Jayakrishna, 2018. A Case Study of 3D Printed PLA and its mechanical properties. Proceedings of the International Conference on Materials Manufacturing and Modelling, (MMM' 18), ACM, pp: 11219- 11226.

DOI: 10.1016/j.matpr.2018.01.146

Sagias, V.D., K.I. Giannakopoulos and C. Stergiou, 2018. Mechanical properties of 3D printed polymer specimens. Proceedings of the 1st International Conference of the Greek Society of Experimental Mechanics of Materials, (EMM' 18), ACM, pp: 85-90. DOI: $10.1016 /$ j.prostr.2018.09.013

Sarvestani, H.Y., A.H. Akbarzadeh, H. Niknam and K. Hermenean, 2018. 3D printed architected polymeric sandwich panels: Energy absorption and structural performance. Comp. Structures, 200: 886-909.

DOI: 10.1016/j.compstruct.2018.04.002

Song, Y., Y. Li, W. Song, K. Yee and K.Y. Lee et al., 2017. Measurements of the mechanical response of unidirectional 3D-printed PLA. Mater. Design, 123: 154-164. DOI: 10.1016/j.matdes.2017.03.051
Sugiyama, K., R. Matsuzaki, M. Ueda, A. Todoroki and Y. Hirano, 2018. 3D printing of composite sandwich structures using continuous carbon fiber and fiber tension. Comp. Part A, 113: 114-121. DOI: 10.1016/j.compositesa.2018.07.029

Torre, R., S. Brischetto, C.G. Ferro and P. Maggiore, 2018. Characterization, in analogy with composites embedding unidirectional long fibres, of PLA specimens produced via FDM printing process. Proceedings of the International Conference on Composite Structures, Sept. 4-7, Bologna, Italy.

Valino, A.D., J.R.C. Dizon, A.H. Espera Jr, Q. Chen and J. Messman et al., 2019. Advances in 3D printing of thermoplastic polymer composites and nanocomposites. Progress Polymer Sci., 98: 101162-101162.

DOI: $10.1016 /$ j.progpolymsci.2019.101162

Wang, X., M. Jiang, Z. Zhou, J. Gou and D. Hui, 2017. 3D printing of polymer matrix composites: A review and prospective. Comp. Part B, 110: 442-458. DOI: 10.1016/j.compositesb.2016.11.034

Yadav, D., D. Chhabra, R.K. Gupta, A. Phogat and A. Ahlawat, 2020. Modeling and analysis of significant process parameters of FDM 3D printer using ANFIS. Mater. Today: Proc., 21: 1592-1604. DOI: $10.1016 /$ j.matpr.2019.11.227

Yang, L., O. Harrysson, H. West and D. Cormier, 2015. Mechanical properties of 3D re-entrant honeycomb auxetic structures realized via additive manufacturing. Int. J. Solids Structures, 69: 475-490. DOI: 10.1016/j.ijsolstr.2015.05.005

Yao, T., Z. Deng, K. Zhang and S. Li, 2019. A method to predict the ultimate tensile strength of $3 \mathrm{D}$ printing Polylactic Acid (PLA) materials with different printing orientations. Comp. Part B, 163: 393-402. DOI: 10.1016/j.compositesb.2019.01.025

Zhao, Y., Y. Chen and Y. Zhou, 2019. Novel mechanical models of tensile strength and elastic property of FDM AM PLA materials: Experimental and theoretical analyses. Mater. Design, 181: 108089. DOI: 10.1016/j.matdes.2019.108089 